\title{
Influence of different dietary fats on triacylglycerol deposition in rat adipose tissue
}

\author{
Javier S. Perona ${ }^{1}$, María P. Portillo², M. Teresa Macarulla ${ }^{2}$, Ana I. Tueros ${ }^{2}$ \\ and Valentina Ruiz-Gutiérrez ${ }^{1 *}$ \\ ${ }^{1}$ Instituto de la Grasa (CSIC), Avda Padre García Tejero 4, 41012 Seville, Spain \\ ${ }^{2}$ Nutrition and Food Science, University of País Vasco, Paseo de la Universidad 7, 01006 Vitoria-Gasteiz, Spain
}

(Received 31 August 1999 - Revised 7 April 2000 - Accepted 9 May 2000)

\begin{abstract}
It has been demonstrated that triacylglycerol (TAG) mobilization from adipose tissue is selective and depends on fatty acid (FA) chain length, unsaturation and positional isomerism. The present study was performed to determine the influence of dietary fat on the composition of TAG stored in rat perirenal and subcutaneous adipose tissues. These results may provide information on the susceptibility of stored TAG to hydrolysis and further mobilization, and may help to establish an interrelationship between dietary composition and the FA efflux from adipose tissue. TAG molecular species and FA composition were determined by HPLC and GLC respectively. No significant differences were found in either FA or TAG composition between perirenal and subcutaneous adipose depots. The major FA in the dietary fats were present in the adipose tissues of the animals; in most cases, in similar proportions. However, differences were found between dietary and adipose tissue content of minor FA, which suggests that dietary FA composition is altered between ingestion and deposition in adipose tissue. The TAG molecular species of rat adipose tissue were enriched with the FA characteristic of each dietary fat. Dietary sunflower oil was responsible for enrichment with the most polar TAG. This finding may suggest easier mobilization of stored TAG. In conclusion, the process of fatty acid and TAG deposition in rat adipose tissue is selective, and depends on the composition of the diet.
\end{abstract}

Triacylglycerol: Adipose tissue: Dietary fat

Adipose tissue accumulates triacyglycerols (TAG) during periods of overfeeding, and releases free fatty acids (FA) during starvation and between meals. Once FA enter the bloodstream, they are involved in several important functions, such as the turnover of cell-membrane lipids or the synthesis of lipid mediators (e.g. eicosanoids; Crawford, 1983). In spite of the importance of the dynamic state of TAG storage and fatty acid release in obesity and its related pathologies, these processes are still incompletely understood.

The deposition and the mobilization of TAG may be influenced by dietary fat. In this context, the influence of dietary FA on the FA profile of membrane adipocytes and its consequences on lipid mobilization have been widely studied. In a previous study performed in our laboratory (Portillo et al. 1999), using the same experimental design as the present study, we found that phospholipids in membrane adipocytes from subcutaneous and perirenal adipose tissues paralleled, to some extent, dietary FA profiles. Some of the changes induced by the dietary lipid source had an effect on lipolytic activity at the $\beta$ adrenoceptor level, but no effects were found at subsequent levels in the adenylate cyclase cascade.

Dietary fat composition may not only influence the FA profile of membrane phospholipids, but also the composition of stored TAG (Ruiz-Gutiérrez et al. 1992). FA deposition in adipose tissue bears some resemblance to the FA composition of the diet (Thomas et al. 1981). Nevertheless, differences between dietary lipids and adipose tissue exist, probably due to intermediate processes between fat ingestion and adipose tissue deposition. It has been demonstrated that endogenous FA are incorporated in

\footnotetext{
Abbreviations: ECN, equivalent carbon number; FA, fatty acid; PR, perirenal; SC, subcutaneous; TAG, triacylglycerol.

* Corresponding author: Valentina Ruiz-Gutiérrez, fax +3454616790, email valruiz@cica.es
} 
the formation of chylomicrons (Lambert et al. 1996). On the other hand, the rates of clearance of TAG during the postprandial period are different among the different molecular species (Botham et al. 1997; Abia et al. 1999) and FA are not released equally from circulating lipoproteins by lipoprotein lipase and transferred to adipose tissue (Wang et al. 1992).

With regard to lipid mobilization, the composition of the TAG stored in adipose tissue is an important factor affecting the release of FA into the bloodstream. Until recently, this process was widely considered to be random. However, it has now been demonstrated that this mobilization is selective and depends on FA chain length, degree of saturation and positional isomerism from adipose tissue (Gavino \& Gavino, 1992; Raclot \& Groscolas, 1995; Raclot et al. 1995; Raclot, 1997). These authors agree that the most easily mobilizable FA are $\mathrm{C}_{16}-\mathrm{C}_{20}$ with four or five double bonds, and that very-long-chain saturated and mono-unsaturated FA $\left(\mathrm{C}_{20}-\mathrm{C}_{24}\right)$ are less mobilizable.

Raclot (1997) also asserts that the polarity of FA affects the hydrolysis process by hormone-sensitive lipase to a greater extent than the position in which these FA are attached. Thus, the accessibility of a TAG molecule to the lipase would be dependent on the polarity resulting from its molecular structure.

The aim of the present study was to determine the influence of different dietary fats on the composition of TAG stored in rat adipose tissue. In order to analyse the involvement of metabolic processes such as de novo FA synthesis in TAG storage, deposition index values were calculated. This index is defined as the relationship between the FA or TAG composition of the adipose tissue and their composition in the ingested fats. These data should provide interesting information which may help to predict the susceptibility to hydrolysis and further mobilization of TAG stored in adipose tissue from rats fed different lipid sources. A possible direct interrelationship between dietary composition and FA efflux from adipose tissue in interdigestion periods may be established. Since it has been widely reported that there are marked metabolic differences in lipid metabolism according to the adipose tissue site (Marchington \& Pond, 1990; Richelsen et al. 1991; Calder et al. 1992; Belzung et al. 1993; Portillo et al. 2000), a comparison was also made between perirenal (PR) and subcutaneous (SC) adipose tissues.

\section{Material and methods}

\section{Animals, diets and experimental design}

Male Wistar rats were purchased from IFFA-Credo (Barcelona, Spain). They were individually housed in a room at $23 \pm 2{ }^{\circ} \mathrm{C}$ and $50 \%$ humidity, with a light-dark cycle of $12 \mathrm{~h}$. Forty 7 -week-old rats, weighing about $215 \mathrm{~g}$, were randomly distributed into four groups of ten rats each. The animals were fed diets enriched in olive oil, beef tallow, sunflower oil or palm oil, which represented $40 \%$ total energy ingested. The composition of the diets and the feeding protocol have been described previously (Portillo et al. 1999). The FA profiles and the TAG species in the dietary fats are shown in Tables 1 and 2. After 4 weeks rats
Table 1. Fatty acid composition of dietary fats ( $g / 100 \mathrm{~g}$ total fatty acids)

\begin{tabular}{lcccr}
\hline Fatty acid & Olive oil & Beef tallow & Sunflower oil & Palm oil \\
\hline $14: 0$ & 0.06 & 4.62 & 0.07 & 1.30 \\
$16: 0$ & 11.88 & 29.50 & 6.35 & 43.94 \\
$18: 0$ & 2.67 & 25.45 & 1.61 & 4.25 \\
$20: 0$ & 0.06 & 0.13 & nd & 0.12 \\
Total SFA & 14.67 & 59.71 & 8.04 & 49.61 \\
$14: 1 n-5$ & nd & 0.62 & nd & 0.05 \\
$16: 1 n-9$ & 0.22 & 0.72 & nd & 0.05 \\
$16: 1 n-7$ & 0.86 & 2.34 & 0.11 & 0.16 \\
$18: 1 n-9$ trans & 0.50 & 7.11 & nd & 0.16 \\
$18: 1 n-9$ & 72.77 & 26.20 & 25.06 & 37.64 \\
$18: 1 n-7$ & 4.40 & 1.59 & 1.56 & 1.69 \\
$20: 1 n-9$ & 0.21 & 0.12 & 0.35 & 0.10 \\
Total MUFA & 78.97 & 38.71 & 27.08 & 39.85 \\
$18: 2 n-6$ & 5.62 & 1.36 & 64.46 & 9.86 \\
$18: 3 n-3$ & 0.74 & 0.22 & 0.42 & 0.58 \\
Total PUFA & 6.37 & 1.58 & 64.88 & 10.44 \\
\hline
\end{tabular}

SFA, saturated fatty acids; MUFA, monounsaturated fatty acids; PUFA, polyunsaturated fatty acids; nd, not detected.

were killed by decapitation after an overnight fast. PR and $\mathrm{SC}$ adipose tissues were removed from the carcasses and weighed. They were immediately frozen in liquid $\mathrm{N}_{2}$ and preserved at $-80^{\circ} \mathrm{C}$ until used.

\section{Sample preparation}

Total lipids were extracted from PR and SC adipose tissues following the method described by Folch et al. (1957). The lipid fractions were separated by TLC on silica gel 60 plates (Kieselgel $60 \mathrm{~F}_{254}$; Merck), using an elution system of hexane-diethyl ether-acetic acid (80:20:1, by vol.;

Table 2. Composition of triacylglycerol (TAG) molecular species of dietary fats ( $\mathrm{g} / 100 \mathrm{~g}$ total $\mathrm{TAG})$

\begin{tabular}{lcccc}
\hline TAG & Olive oil & Beef tallow & Sunflower oil & Palm oil \\
\hline LLLn & nd & nd & 1.36 & nd \\
OLnLn & nd & nd & 0.04 & nd \\
PLnLn & nd & nd & 0.08 & nd \\
LLL & 0.01 & 0.01 & 8.21 & 0.10 \\
OLLn & nd & nd & 0.25 & nd \\
SLnLn & nd & nd & 1.54 & nd \\
MLL & nd & nd & 5.05 & nd \\
MML & nd & nd & 0.30 & 0.54 \\
OLL(OOLn) & 0.13 & 0.13 & 12.37 & 0.96 \\
PLL(POLn) & 0.41 & 0.21 & 41.75 & 3.88 \\
PMM & 0.19 & 0.16 & 0.67 & 1.07 \\
OOL & 2.24 & 1.60 & 2.92 & 2.31 \\
POL(SLL) & 9.62 & 4.03 & 22.55 & 34.54 \\
PPL & 0.12 & 1.75 & 0.33 & 1.40 \\
OOO & 65.60 & 11.52 & 0.18 & 2.79 \\
POO & 19.89 & 22.17 & 2.02 & 47.05 \\
PPO & 1.20 & 9.85 & 0.18 & 4.71 \\
PPP & 0.05 & 0.99 & 0.13 & 0.15 \\
PMS & nd & 5.57 & nd & nd \\
SOO & 0.34 & 18.87 & 0.04 & 0.23 \\
POS & 0.10 & 12.61 & nd & 0.25 \\
SSO & nd & 6.26 & nd & nd \\
SSP & nd & 4.27 & nd & nd \\
\hline
\end{tabular}

M, myristic acid, 14:0; P, palmitic acid, 16:0; S, stearic acid, 18:0; O, oleic acid 18:1; L, linoleic acid, 18:2; Ln, linolenic acid, 18:3; PPP, tripalmitoyl-glycerol; PMS, palmitoyl-myristoyl-stearoyl-glycerol; PLL, palmitoyl-dilinoleoyl-glycerol, nd, not detected. 
Merck), according to the method of Ruiz-Gutiérrez et al. (1992). The TAG fraction was scraped off the silica, eluted with hexane-diethyl ether $(9: 1, \mathrm{v} / \mathrm{v})$, passed through a stream of $\mathrm{N}_{2}$ and stored below $-20^{\circ} \mathrm{C}$ until analysed.

\section{Fatty acid analysis}

TAG were transmethylated and the resulting fatty acid methyl esters analysed by GLC as described by RuizGutiérrez et al. (1992) using a model 5890 series II gas chromatograph (Hewlett-Packard, Avondale, PA, USA) equipped with a flame-ionization detector and a capillary silica column Supelcowax 10 (Sulpelco, Bellefonte, PA, USA) of $60 \mathrm{~m}$ length and $0 \cdot 25 \mathrm{~mm}$ i.d.

The relationship between the FA composition of the adipose tissue and the composition of the fats ingested was used to calculate the FA deposition index for each FA. Only those FA found in the dietary fats were considered for this determination.

\section{Triacylglycerol molecular species analysis}

TAG, were evaporated to dryness under a vacuum, redissolved in $n$-hexane and passed through a filter with a pore size of $0.2 \mathrm{~mm}$ (Millipore, Bedford, MA, USA). The chromatographic system consisted of a model 2690 with a particle size of $3 \mu \mathrm{m}$ (Phase Separations, Waters, Milford, MA, USA) and a column dead time of 1.99 min, according to the supplier. The mobile phase consisted of an initial elution gradient of $20 \%(\mathrm{v} / \mathrm{v})$ acetone in acetonitrile, with the percentage of acetone increasing to $45 \%(\mathrm{v} / \mathrm{v})$ at $4 \mathrm{~min}$ and finally to $80 \%(\mathrm{v} / \mathrm{v})$ at $40 \mathrm{~min}$, which was maintained to the end of the analysis. The flow rate was $1.0 \mathrm{ml} / \mathrm{min}$. The liquid chromatograph was coupled to a light-scattering detector model DDL31 (Eurosep Instruments, CergyPontoise, France). The system was controlled by a computer through Millenium Software (Waters Co., Milford, MA, USA). Sigmoidal response curves were observed for all the standards determined. However, linear regression may also be valid $\left(\mathrm{r}^{2} 0.984-0.995\right)$ in the range of concentrations studied (between 0.25 and $2.5 \mathrm{mg} / \mathrm{ml}$; Perona \& Ruiz-Gutiérrez, 1999). Runs of $10 \mu$ l of a $n$ hexane solution containing pure TAG (Sigma grade, $99 \%$ pure; Sigma, St Louis, MO, USA; $0.5 \mathrm{mg} / \mathrm{ml}$ ): tritridecanoin, 1,3-dioleoyl-2-palmitoyl-glycerol, trimyristin, 1,3dioleoyl-2-stearoyl-glycerol, 1,3-dioleoyl-2-linoleoyl-glycerol, tripentadecanoin, tripalmitin, triolein and trilinolein) were injected in quintuplicate in order to establish the capacity factor of the system. All the solvents used, both in dissolving sample TAG and in the mobile phase, were HPLC grade (Merck). The TAG composition was predicted by means of the relationship between the capacity factor and molecular variables of pure triacylglycerols.

The values of the equivalent $\mathrm{C}$ number $(\mathrm{ECN})$ were calculated as $\mathrm{ECN}=\mathrm{CN}-2 \mathrm{ND}-2 \mathrm{NUFA}$, where $\mathrm{CN}$ is the number of $\mathrm{C}$ atoms, $\mathrm{ND}$ the number of double bonds and NUFA the number of unsaturated FA attached to the glycerol molecule. A linear regression analysis was applied to relate the ECN to the log of the capacity factor for the pure TAG. The TAG composition of the samples was calculated by comparison of the ECN of the chromatographic peaks and the theoretical ECN of all possible TAG. These data were calculated by combination of FA obtained in the GLC analysis in groups of three. We considered all the stereospecific positions in the glycerol backbone as equivalents, since HPLC cannot separate positional isomers (Perona et al. 1998a; Perona \& Ruiz-Gutiérrez, 1998). TAG were quantified using tridecanoin as internal standard. The method was adapted from Nájera et al. (1998).

The deposition indexes, calculated as the relationship between the TAG composition of the adipose tissue and the composition of the fats ingested for each TAG molecular species, were plotted $v$. ECN of each TAG, which was taken as an index of polarity, since TAG molecules elute from the HPLC column in increasing ECN in a reversedphase system. Thus, the lowest ECN values correspond to the most polar molecules and the highest to the most apolar ones.

\section{Statistical analysis}

The significance of the differences among the dietary groups and between anatomical sites of adipose tissue was assessed by one-way ANOVA with unpaired Student's $t$ test for multiple comparisons. Pearson correlation coefficients were calculated to examine the relationship between TAG deposition index and ECN. All comparisons were considered statistically significant at $P<0.05$. The analyses were done with the GraphPAD InStat (GraphPAD Software, San Diego, CA, USA) and CoStat (CoHort Software, Minneapolis, MN, USA).

\section{Results}

Animals fed diets enriched with different fats showed a similar weight gain during the experimental period. The weight of adipose tissue from each anatomical site was also similar in all the groups (Portillo et al. 1999).

The FA composition of the TAG stored in adipose tissues is shown in Tables 3 (PR) and 4 (SC). Significant differences were found among rats fed the different experimental diets. The content of oleic acid (18:1n-9) was higher in the adipose tissue of rats fed olive oil (59.73 g/100 g total FA for PR and 57.22 g/100 g total FA for SC). This finding was reflected in the global content of monounsaturated FA, which accounted for approximately $70 \%$ of the total FA. Relatively high amounts of palmitic (16:0; $16.67 \mathrm{~g} / 100 \mathrm{~g}$ total FA for PR and $16.71 \mathrm{~g} / 100 \mathrm{~g}$ total FA for SC) and linoleic $(18: 2 n-6 ; 10 \cdot 60 \mathrm{~g} / 100 \mathrm{~g}$ total FA for PR and $13.06 \mathrm{~g} / 100 \mathrm{~g}$ total FA for SC) acids were found in the adipose tissues of rats fed olive oil. The adipose tissue of rats fed beef tallow showed a greater accumulation of saturated FA, than that of rats fed the other diets. Myristic acid (14:0) accounted for $2.69 \mathrm{~g} / 100 \mathrm{~g}$ total FA in PR and 3.35 g/100 g total FA in SC, palmitic acid (16:0) reached approximately $30 \mathrm{~g} / 100 \mathrm{~g}$ total FA in both sites and stearic acid (18:0) was detected at levels of $7 \mathrm{~g} /$ $100 \mathrm{~g}$ total FA for PR and $8 \mathrm{~g} / 100 \mathrm{~g}$ total FA for SC. The content of elaidic acid (18:1n-9 trans, $2.87 \mathrm{~g} / 100 \mathrm{~g}$ total FA for PR and $2.93 \mathrm{~g} / 100 \mathrm{~g}$ total FA for SC) was also higher in the adipose tissue of rats fed beef tallow. The 
Table 3. Fatty acid composition ( $\mathrm{g} / 100 \mathrm{~g}$ total fatty acids) of perirenal adipose tissue from rats fed the experimental diets* (Values expressed as means and standard deviations)

\begin{tabular}{|c|c|c|c|c|c|c|c|c|}
\hline \multirow[b]{2}{*}{ Fatty acids } & \multicolumn{2}{|c|}{ Olive oil } & \multicolumn{2}{|c|}{ Beef tallow } & \multicolumn{2}{|c|}{ Sunflower oil } & \multicolumn{2}{|c|}{ Palm oil } \\
\hline & Mean & SD & Mean & SD & Mean & SD & Mean & SD \\
\hline $14: 0$ & $0.76^{a}$ & 0.06 & $2 \cdot 69^{b}$ & 0.31 & $0.94^{a}$ & 0.13 & $1.26^{a}$ & 0.21 \\
\hline $16: 0$ & $16 \cdot 67^{\mathrm{a}}$ & 0.85 & $25 \cdot 38^{\mathrm{b}}$ & 0.72 & $16 \cdot 45^{\mathrm{a}}$ & 1.40 & $29 \cdot 32^{c}$ & 0.54 \\
\hline $18: 0$ & $2 \cdot 46^{\mathrm{a}}$ & 0.15 & $7.07^{b}$ & 0.53 & $3 \cdot 21^{a}$ & 0.29 & $2.95^{a}$ & 0.24 \\
\hline $20: 0$ & 0.29 & 0.01 & 0.21 & 0.02 & 0.05 & 0.02 & 0.03 & 0.01 \\
\hline $22: 0$ & 0.08 & 0.02 & 0.08 & 0.02 & nd & nd & 0.06 & 0.01 \\
\hline Total SFA & $20 \cdot 02^{a}$ & 1.03 & $35 \cdot 39^{b}$ & 1.09 & $21 \cdot 08^{a}$ & 0.94 & $33 \cdot 74^{b}$ & 0.53 \\
\hline $14: 1 n-5$ & 0.18 & 0.09 & 0.33 & 0.12 & 0.15 & 0.01 & 0.15 & 0.03 \\
\hline $16: 1 n-9$ & 0.46 & 0.06 & 0.53 & 0.04 & 0.25 & 0.06 & 0.34 & 0.04 \\
\hline $16: 1 n-7$ & $2.42^{\mathrm{a}}$ & 0.40 & $5 \cdot 23^{b}$ & 0.48 & $2.98^{a}$ & 0.97 & $3 \cdot 19^{a}$ & 0.81 \\
\hline $18: 1 n-9$ trans & $0.03^{\mathrm{a}}$ & 0.00 & $2 \cdot 87^{b}$ & 0.31 & $0.08^{a}$ & 0.02 & $0 \cdot 16^{\mathrm{a}}$ & 0.06 \\
\hline $18: 1 n-9$ & $59 \cdot 73^{a}$ & $1 \cdot 71$ & $41.40^{\mathrm{b}}$ & 1.36 & $26 \cdot 51^{\mathrm{c}}$ & 0.64 & $45 \cdot 17^{b}$ & $2 \cdot 30$ \\
\hline $18: 1 n-7$ & $4 \cdot 74^{a}$ & 0.39 & $4 \cdot 65^{a}$ & 0.20 & $2 \cdot 34^{\mathrm{b}}$ & 0.33 & $3 \cdot 38^{\mathrm{b}}$ & 0.15 \\
\hline $20: 1 n-9$ & 0.14 & 0.02 & 0.21 & 0.02 & 0.16 & 0.02 & 0.23 & 0.03 \\
\hline $20: 1 n-7$ & nd & nd & nd & nd & 0.21 & 0.03 & 0.19 & 0.03 \\
\hline $24: 1 n-9$ & nd & nd & nd & nd & 0.06 & 0.02 & 0.20 & 0.03 \\
\hline Total MUFA & $67.99^{a}$ & 1.29 & $55.49^{b}$ & 1.75 & $32.46^{\mathrm{C}}$ & 1.77 & $52 \cdot 62^{\mathrm{b}}$ & $2 \cdot 15$ \\
\hline $18: 2 n-6$ & $10 \cdot 60^{\mathrm{a}}$ & 1.03 & $7 \cdot 91^{a}$ & 1.70 & $45 \cdot 04^{b}$ & $2 \cdot 84$ & $12 \cdot 77^{\mathrm{a}}$ & $2 \cdot 14$ \\
\hline $20: 2 n-6$ & 0.04 & 0.01 & nd & nd & 0.22 & 0.06 & 0.03 & 0.04 \\
\hline $20: 3 n-6$ & $0 \cdot 10$ & 0.02 & 0.09 & 0.03 & 0.09 & 0.05 & 0.06 & 0.01 \\
\hline $20: 4 n-6$ & 0.19 & 0.05 & nd & nd & 0.61 & 0.30 & 0.15 & 0.03 \\
\hline $22: 5 n-6$ & nd & nd & nd & nd & 0.42 & 0.31 & 0.02 & 0.01 \\
\hline Total PUFA $n-6$ & $10 \cdot 93^{\mathrm{a}}$ & 1.09 & $8 \cdot 00^{a}$ & 1.68 & $46 \cdot 38^{b}$ & 2.38 & $13 \cdot 03^{a}$ & $2 \cdot 21$ \\
\hline $18: 3 n-3$ & 0.63 & 0.27 & 0.74 & 0.13 & 0.41 & 0.07 & 0.30 & 0.04 \\
\hline $22: 6 n-3$ & 0.02 & 0.01 & 0.12 & 0.05 & nd & nd & nd & nd \\
\hline Total PUFA $n-3$ & 0.65 & 0.28 & 0.86 & 0.15 & 0.41 & 0.07 & 0.30 & 0.04 \\
\hline
\end{tabular}

a,b,c Mean values within a row with unlike superscript letters were significantly different $(P<0.05, t$ test).

SFA, saturated fatty acids, MUFA, monounsaturated fatty acids; PUFA, polyunsaturated fatty acids; nd, not detected.

* For details of fatty acid and triacylglycerol composition of dietary fats, see Tables 1 and 2, and for details of experimental procedures, see p. 766 .

Table 4. Fatty acid composition ( $\mathrm{g} / 100 \mathrm{~g}$ total fatty acids) of subcutaneous adipose tissue from rats fed the experimental diets* (Values expressed as means and standard deviations)

\begin{tabular}{|c|c|c|c|c|c|c|c|c|}
\hline \multirow[b]{2}{*}{ Fatty acids } & \multicolumn{2}{|c|}{ Olive oil } & \multicolumn{2}{|c|}{ Beef tallow } & \multicolumn{2}{|c|}{ Sunflower oil } & \multicolumn{2}{|c|}{ Palm oil } \\
\hline & Mean & SD & Mean & SD & Mean & SD & Mean & SD \\
\hline $14: 0$ & $0.91^{a}$ & 0.14 & $3.35^{\mathrm{b}}$ & 0.19 & $1.05^{a}$ & 0.09 & $1 \cdot 21^{a}$ & 0.23 \\
\hline $16: 0$ & $16 \cdot 71^{a}$ & 1.65 & $29 \cdot 49^{\mathrm{b}}$ & 0.58 & $16 \cdot 12^{\mathrm{a}}$ & $2 \cdot 19$ & $26 \cdot 57^{\mathrm{b}}$ & 1.47 \\
\hline $18: 0$ & $2.50^{\mathrm{a}}$ & 0.20 & $8 \cdot 27^{b}$ & 0.05 & $3.38^{a}$ & 0.07 & $3 \cdot 24^{a}$ & 0.44 \\
\hline $20: 0$ & $0.05^{a}$ & 0.01 & $0.25^{b}$ & 0.02 & $0.04^{a}$ & 0.00 & $0.03^{a}$ & 0.00 \\
\hline $22: 0$ & nd & nd & 0.41 & $0 \cdot 15$ & 0.05 & 0.01 & 0.03 & 0.00 \\
\hline Total SFA & $20 \cdot 14^{a}$ & 1.56 & $40 \cdot 89^{b}$ & 0.67 & $20 \cdot 58^{a}$ & $2 \cdot 26$ & $31.05^{c}$ & 1.32 \\
\hline $14: 1 n-5$ & 0.15 & 0.02 & 0.67 & 0.02 & 0.14 & 0.03 & 0.19 & 0.02 \\
\hline $16: 1 n-9$ & 0.58 & 0.02 & 0.50 & 0.08 & 0.28 & 0.02 & 0.36 & 0.04 \\
\hline $16: 1 n-7$ & $2 \cdot 83$ & 0.83 & 3.86 & 0.07 & $2 \cdot 47$ & 0.46 & $2 \cdot 06$ & 0.02 \\
\hline $18: 1 n-9$ trans & $0 \cdot 12^{\mathrm{a}}$ & 0.05 & $3 \cdot 26^{b}$ & 0.08 & $0.09^{a}$ & 0.04 & $0.11^{\mathrm{a}}$ & 0.02 \\
\hline $18: 1 n-9$ & $57 \cdot 22^{a}$ & 3.90 & $33.93^{b}$ & 0.91 & $26 \cdot 55^{\mathrm{b}}$ & $1 \cdot 13$ & $45 \cdot 10^{\mathrm{C}}$ & 1.54 \\
\hline $18: 1 n-7$ & $4 \cdot 24^{a}$ & 0.21 & $3.90^{\mathrm{a}}$ & 0.23 & $2 \cdot 21^{b}$ & 0.18 & $2 \cdot 82^{b}$ & 0.40 \\
\hline $20: 1 n-9$ & 0.30 & 0.04 & 0.38 & 0.02 & 0.19 & 0.02 & 0.20 & 0.03 \\
\hline $20: 1 n-7$ & $0 \cdot 18$ & 0.04 & nd & nd & 0.30 & 0.03 & 0.21 & 0.04 \\
\hline $24: 1 n-9$ & 0.09 & 0.06 & 0.08 & $0 \cdot 12$ & nd & nd & 0.11 & 0.20 \\
\hline Total MUFA & $65 \cdot 71^{\mathrm{a}}$ & 2.93 & $45 \cdot 49^{b}$ & 0.22 & $32 \cdot 23^{\mathrm{C}}$ & 1.45 & $50 \cdot 39^{b}$ & 1.97 \\
\hline $18: 2 n-6$ & $13 \cdot 06^{a}$ & $1 \cdot 17$ & $10 \cdot 23^{a}$ & 0.21 & $44 \cdot 47^{\mathrm{b}}$ & 3.92 & $16 \cdot 04^{a}$ & $2 \cdot 28$ \\
\hline $20: 2 n-6$ & 0.08 & 0.03 & nd & nd & 0.20 & 0.06 & 0.15 & $0 \cdot 13$ \\
\hline $20: 3 n-6$ & 0.06 & 0.05 & nd & nd & 0.14 & 0.04 & 0.08 & 0.06 \\
\hline $20: 4 n-6$ & 0.13 & 0.09 & nd & nd & 0.73 & 0.35 & 0.21 & 0.04 \\
\hline $22: 5 n-6$ & 0.16 & 0.12 & 0.05 & $0 \cdot 11$ & 0.20 & 0.09 & 0.13 & $0 \cdot 14$ \\
\hline Total PUFAn-6 & $13.49^{\mathrm{a}}$ & 1.21 & $10 \cdot 28^{a}$ & 0.21 & $45 \cdot 74^{\mathrm{b}}$ & 4.03 & $16 \cdot 61^{a}$ & $2 \cdot 36$ \\
\hline $18: 3 n-3$ & 0.60 & 0.13 & 0.73 & 0.05 & 0.35 & $0 \cdot 16$ & 0.51 & 0.02 \\
\hline $22: 6 n-3$ & nd & nd & nd & nd & 0.05 & 0.02 & nd & nd \\
\hline Total PUFAn-3 & 0.60 & 0.13 & 0.73 & 0.05 & 0.40 & 0.18 & 0.51 & 0.02 \\
\hline
\end{tabular}

a,b,c Mean values within a row with unlike superscript letters were significantly different $(P<0.05, t$ test).

SFA, Saturated fatty acids; MUFA, monounsaturated fatty acids; PUFA, polyunsaturated fatty acids; nd, not detected.

${ }^{*}$ For details of fatty acid and triacylglycerol composition and dietary fats, see Tables 1 and 2 , and for details of experimental procedures, see p. 766 . 
Table 5. Composition of triacylglycerol (TAG) molecular species ( $\mathrm{g} / 100 \mathrm{~g}$ total TAG) of perirenal adipose tissue from rats fed the experimental diets $^{*}$

(Values expressed as means and standard deviations)

\begin{tabular}{|c|c|c|c|c|c|c|c|c|}
\hline \multirow[b]{2}{*}{ TAG } & \multicolumn{2}{|c|}{ Olive oil } & \multicolumn{2}{|c|}{ Beef tallow } & \multicolumn{2}{|c|}{ Sunflower oil } & \multicolumn{2}{|c|}{ Palm oil } \\
\hline & Mean & SD & Mean & SD & Mean & SD & Mean & SD \\
\hline LLLn & nd & nd & nd & nd & 0.03 & 0.01 & nd & nd \\
\hline OLnLn & nd & nd & nd & nd & 0.02 & 0.01 & nd & nd \\
\hline PLnLn & nd & nd & nd & nd & nd & nd & nd & nd \\
\hline MMLn & nd & nd & nd & nd & 0.04 & 0.02 & nd & nd \\
\hline LLL & $0.05^{a}$ & 0.03 & $0.04^{a}$ & 0.01 & $10.58^{\mathrm{b}}$ & $1 \cdot 14$ & $0.04^{a}$ & 0.02 \\
\hline OLLn & 0.05 & 0.02 & 0.03 & 0.01 & 0.25 & 0.03 & 0.02 & 0.01 \\
\hline SLnLn & 0.02 & 0.00 & 0.05 & 0.02 & 0.08 & 0.01 & 0.02 & 0.01 \\
\hline PLLn & 0.03 & 0.02 & nd & nd & 0.09 & 0.08 & 0.02 & 0.02 \\
\hline MLL & 0.01 & 0.01 & 0.02 & 0.01 & 0.05 & 0.05 & 0.02 & 0.01 \\
\hline MML & 0.02 & 0.01 & 0.02 & 0.02 & 0.02 & 0.01 & 0.02 & 0.01 \\
\hline OLL(OOLn) & $1.58^{a}$ & 0.61 & $0.44^{\mathrm{a}}$ & 0.31 & $17 \cdot 73^{b}$ & $4 \cdot 17$ & $1.34^{\mathrm{a}}$ & 0.84 \\
\hline PLL(POLn) & $1.84^{\mathrm{a}}$ & 0.91 & $1 \cdot 17^{\mathrm{a}}$ & 0.40 & $16 \cdot 36^{\mathrm{b}}$ & $2 \cdot 82$ & $3.58^{a}$ & 1.41 \\
\hline PPLn & 0.08 & 0.05 & 0.38 & 0.12 & 0.28 & 0.14 & 0.17 & 0.04 \\
\hline LPM & 0.08 & 0.03 & 0.30 & 0.12 & 0.34 & 0.28 & 0.17 & 0.07 \\
\hline OMM & 0.04 & 0.03 & 0.19 & 0.14 & 0.06 & 0.01 & 0.02 & 0.01 \\
\hline PMM & $0.02^{\mathrm{a}}$ & 0.02 & nd & nd & nd & nd & $0.01^{a}$ & 0.01 \\
\hline OOL & $17 \cdot 80^{\mathrm{a}}$ & 1.76 & $4.40^{\mathrm{b}}$ & 1.02 & $11.96^{\mathrm{a}}$ & 3.05 & $12 \cdot 56^{\mathrm{a}}$ & 2.91 \\
\hline POL(SLL) & 14.79 & $2 \cdot 81$ & 13.91 & 2.44 & 21.35 & 3.64 & $19 \cdot 46$ & 3.01 \\
\hline PPL & $1.52^{\mathrm{a}}$ & 0.60 & $1 \cdot 74^{\mathrm{a}}$ & 0.43 & $4.78^{\mathrm{b}}$ & 1.66 & $6 \cdot 39^{b}$ & $2 \cdot 84$ \\
\hline PSLn & nd & nd & $2.98^{a}$ & 0.93 & $0.07^{b}$ & 0.01 & $0.06^{b}$ & 0.06 \\
\hline PPPo & 0.11 & 0.05 & 0.83 & 0.26 & 0.18 & 0.08 & 0.13 & 0.04 \\
\hline 000 & $25 \cdot 26^{a}$ & $6 \cdot 15$ & $10 \cdot 23^{b}$ & 0.62 & $2 \cdot 55^{\mathrm{c}}$ & 1.65 & $12 \cdot 81^{\mathrm{b}}$ & 1.54 \\
\hline $\mathrm{POO}$ & $24.58^{\mathrm{a}}$ & 4.97 & $37.58^{b}$ & 3.06 & $9 \cdot 40^{\mathrm{C}}$ & 4.50 & $22 \cdot 98^{\mathrm{a}}$ & 4.39 \\
\hline PPO & $4 \cdot 86^{a}$ & 0.80 & $16 \cdot 28^{b}$ & 2.91 & $2 \cdot 86^{a}$ & 0.43 & $16 \cdot 88^{b}$ & 1.84 \\
\hline PPP & $0 \cdot 15^{a}$ & 0.03 & $1.51^{\mathrm{b}}$ & 0.46 & $0.49^{a}$ & 0.60 & $1.02^{b}$ & 0.27 \\
\hline SOO & 0.12 & 0.06 & 0.33 & 0.07 & nd & nd & 0.05 & 0.02 \\
\hline POS & $2 \cdot 08^{a}$ & 0.54 & $3.98^{b}$ & 0.47 & $0.17^{\mathrm{c}}$ & 0.02 & $1.06^{a}$ & 0.08 \\
\hline SSO & $0.47^{a}$ & 0.19 & $3.63^{b}$ & 0.70 & $0 \cdot 31^{a}$ & 0.21 & $1 \cdot 17^{a}$ & 0.08 \\
\hline
\end{tabular}

a,b,c Mean values within a row with unlike superscript letters were significantly different $(P<0.05, t$ test).

M, myristic acid, 14:0; P, palmitic acid, 16:0; S, stearic acid, 18:0; Po, palmitoleic, 16:1; O, oleic acid, 18:1; L, linoleic acid, 18:2; Ln, linolenic acid, 18:3; PPP, tripalmitoyl-glycerol; PSLn, palmitoyl-stearoyl-linolenoyl-glycerol; PLL, palmitoyl-dilinoleoyl-glycerol; nd, not detected.

* For details of fatty acid and triacylglycerol composition of dietary fat, see Tables 1 and 2, and for details of experimental procedures, see p. 766 .

adipose tissue of rats fed sunflower oil was characterized by a high content of linoleic acid (45.04 g/100 g total FA for PR and $44.47 \mathrm{~g} / 100 \mathrm{~g}$ total FA for SC) and derivatives of the $n-6$ family, with a concomitant decrease in monounsaturated and saturated FA. Palmitic and oleic acids accounted for approximately $70 \mathrm{~g} / 100 \mathrm{~g}$ total FA in the adipose tissue of rats fed palm oil.

Tables 5 and 6 show the TAG molecular species composition of rat PR and SC adipose tissues respectively. An HPLC chromatogram of adipose tissue TAG species profile is shown in Fig. 1. Oleic acid-containing TAG were significantly enhanced in the adipose tissue of rats fed olive oil. Triolein $(25.26 \mathrm{~g} /$ total TAG for PR and $25.84 \mathrm{~g} / 100 \mathrm{~g}$ total TAG for SC) and dioleoyl-linoleoyl-glycerol (17.80 g/ $100 \mathrm{~g}$ total TAG for PR and $18.53 \mathrm{~g} / 100 \mathrm{~g}$ total TAG for $\mathrm{SC})$ showed higher concentrations than in rats fed the other dietary fats. As expected, the adipose tissue of rats fed beef tallow was enriched in those TAG formed with palmitic and stearic acids (palmitoyl-dioleoyl-glycerol, dipalmitoyloleoyl-glycerol, palmitoyl-oleoyl-stearoyl-glycerol and distearoyl-oleoyl-glycerol). In addition, a high amount of palmitoyl-stearoyl-linolenoyl-glycerol was found $(2.98 \mathrm{~g} /$ $100 \mathrm{~g}$ total TAG for PR and $4.67 \mathrm{~g} / 100 \mathrm{~g}$ total TAG for $\mathrm{SC}$ ) compared with rats in the other dietary groups, in which only traces were found. Sunflower oil was responsible for an elevation of the content of linoleic acid-containing species (trilinolein, oleoyl-dilinoleoyl-gly- cerol and palmitoyl-dilinoleoyl-glycerol). When palm oil was administered to rats, the adipose tissue showed higher contents of palmitoyl species (dipalmitoyl-linoleoyl-glycerol and dipalmitoyl-oleoyl-glycerol). The TAG molecule comprising the three main FA present in the dietary fats studied, i.e. palmitoyl-oleoyl-linoleoyl-glycerol, was not found in significantly different amounts in the adipose tissue from the different dietary groups.

When PR and SC adipose tissues were compared, slight differences were only observed in the rats fed beef tallow. In this group, the content of oleic acid (18:1n-9) was significantly higher $(P<0.05)$ in PR than in SC. With regard to TAG molecular species composition, a significantly higher amount of palmitoyl-dioleoyl-glycerol $(P<$ $0 \cdot 05)$ and a significantly lower amount of oleoyl-dilinoleoyl-glycerol and palmitoyl-dilinoleoyl-glycerol $(P<$ $0.05)$ were found in PR. For clarity, these data are not shown in Tables 3-6.

Values for the deposition index for FA from dietary fats are shown in Table 7. Rats fed olive oil showed a greater deposition of linoleic acid at both sites of adipose tissue (1.89 for PR and 2.32 for SC), compared with the other main FA present in olive oil. However, this effect was more evident in rats fed beef tallow, with deposition indexes of 5.80 and 7.28 for PR and SC adipose tissues respectively, although this FA was less prevalent in beef tallow than in olive oil. On the contrary, stearic acid was deposited at very 
Table 6. Composition of triacylglycerol (TAG) molecular species $(\mathrm{g} / 100 \mathrm{~g}$ total TAG) of subcutaneous adipose tissue from rats fed the experimental diets

(Values expressed as means and standard deviations)

\begin{tabular}{|c|c|c|c|c|c|c|c|c|}
\hline \multirow[b]{2}{*}{ TAG } & \multicolumn{2}{|c|}{ Olive oil } & \multicolumn{2}{|c|}{ Beef tallow } & \multicolumn{2}{|c|}{ Sunflower oil } & \multicolumn{2}{|c|}{ Palm oil } \\
\hline & Mean & SD & Mean & SD & Mean & SD & Mean & SD \\
\hline LLLn & 0.02 & 0.01 & nd & nd & 0.03 & 0.01 & 0.01 & 0.01 \\
\hline OLnLn & nd & nd & 0.02 & 0.01 & 0.02 & 0.01 & 0.01 & 0.00 \\
\hline PLnLn & nd & nd & 0.03 & 0.02 & 0.09 & 0.06 & 0.03 & 0.03 \\
\hline LLL & $0.16^{\mathrm{a}}$ & 0.11 & $0.11^{\mathrm{a}}$ & 0.07 & $9 \cdot 80^{\mathrm{b}}$ & 3.14 & $0.20^{\mathrm{a}}$ & 0.04 \\
\hline OLLn & 0.08 & 0.06 & 0.05 & 0.02 & 0.27 & 0.08 & 0.11 & 0.08 \\
\hline SLnLn & 0.03 & 0.02 & 0.07 & 0.01 & 0.23 & 0.14 & 0.12 & 0.08 \\
\hline PLLn & 0.06 & 0.05 & 0.08 & 0.05 & 0.23 & 0.11 & $0 \cdot 16$ & 0.08 \\
\hline MLL & 0.02 & 0.01 & 0.05 & 0.04 & 0.24 & 0.09 & 0.04 & 0.02 \\
\hline MML & nd & nd & 0.07 & 0.05 & 0.05 & 0.02 & 0.06 & 0.04 \\
\hline OLL(OOL) & $2 \cdot 33^{\mathrm{a}}$ & 1.42 & $1.78^{\mathrm{a}}$ & 0.39 & $19 \cdot 48^{\mathrm{b}}$ & 4.04 & $2 \cdot 86^{\mathrm{a}}$ & 1.33 \\
\hline PLL(POLn) & $3 \cdot 61^{a}$ & $1 \cdot 10$ & $3 \cdot 34^{a}$ & 1.03 & $16 \cdot 23^{b}$ & 1.98 & $3 \cdot 91^{a}$ & 2.05 \\
\hline PPLn & 0.45 & 0.05 & nd & nd & 0.33 & 0.10 & 0.29 & 0.11 \\
\hline LPM & 0.16 & 0.08 & 0.40 & 0.16 & nd & nd & nd & nd \\
\hline OMM & 0.06 & 0.04 & 0.57 & 0.33 & 0.10 & 0.04 & 0.05 & 0.03 \\
\hline PMM & 0.03 & 0.02 & nd & nd & nd & nd & 0.06 & 0.04 \\
\hline $\mathrm{OOL}$ & $18 \cdot 53^{\mathrm{a}}$ & 1.28 & $4 \cdot 10^{b}$ & 0.70 & $13 \cdot 69^{c}$ & $1 \cdot 10$ & $13 \cdot 74^{\mathrm{C}}$ & 1.37 \\
\hline POL(SLL) & $15 \cdot 46$ & 2.68 & 21.91 & $2 \cdot 76$ & $20 \cdot 86$ & 2.69 & $20 \cdot 35$ & $2 \cdot 51$ \\
\hline PPL & $1.69^{\mathrm{a}}$ & 0.72 & $3.53^{b}$ & 0.33 & $3 \cdot 31^{b}$ & 0.94 & $3.56^{b}$ & 1.12 \\
\hline PSLn & nd & nd & $4 \cdot 67^{a}$ & 1.43 & $0.03^{b}$ & 0.02 & nd & nd \\
\hline PPPo & 0.13 & 0.05 & 1.14 & 0.40 & 0.16 & 0.07 & 0.16 & 0.12 \\
\hline 000 & $25 \cdot 84^{\mathrm{a}}$ & $7 \cdot 25$ & $10 \cdot 23^{\mathrm{b}}$ & 1.73 & $1.63^{c}$ & 0.37 & $11 \cdot 34^{\mathrm{b}}$ & $2 \cdot 30$ \\
\hline POO & $23 \cdot 89^{a}$ & 4.30 & $21.53^{\mathrm{a}}$ & 1.89 & $6 \cdot 28^{\mathrm{b}}$ & 0.74 & $22 \cdot 75^{\mathrm{a}}$ & 5.01 \\
\hline PPO & $4 \cdot 75^{\mathrm{a}}$ & 1.76 & $14 \cdot 86^{b}$ & $3 \cdot 14$ & $5 \cdot 46^{\mathrm{a}}$ & 3.97 & $15 \cdot 49^{b}$ & 1.78 \\
\hline PPP & $0 \cdot 17^{\mathrm{a}}$ & 0.07 & $1.63^{b}$ & 0.42 & $0.95^{a}$ & 0.48 & $1 \cdot 12^{b}$ & 0.42 \\
\hline SOO & 0.15 & 0.09 & 0.31 & 0.09 & 0.08 & 0.04 & 0.11 & 0.04 \\
\hline POS & $1.72^{\mathrm{a}}$ & 0.35 & $4 \cdot 27^{b}$ & 0.65 & $0.27^{\mathrm{C}}$ & 0.01 & $1.69^{\mathrm{a}}$ & 0.46 \\
\hline SSO & $0.68^{\mathrm{a}}$ & 0.29 & $4 \cdot 24^{\mathrm{b}}$ & 0.18 & $0.20^{\mathrm{a}}$ & 0.09 & $1.78^{\mathrm{C}}$ & 0.64 \\
\hline
\end{tabular}

${ }^{\mathrm{a}, \mathrm{b}, \mathrm{c}}$ Mean values within a row with unlike superscript letters were significantly different $(P<0.05, t$ test).

M, myristic acid, 14:0; P, palmitic acid, 16:0; S, stearic acid, 18:0; Po, palmitoleic, 16:1; O, Oleic acid, 18:1; L, linoleic acid, 18:2; Ln, linolenic acid, 18:3; PPP, tripalmitoyl-glycerol; PSLn, palmitoyl-stearoyl-linolenoyl-glycerol; PLL, palmitoyl-dilinoleoyl-glycerol; nd, not detected.

* For details of fatty acids and triacylglycerol composition of dietary fat, see Tables 1 and 2, and for details of experimental procedures, see p. 766.

low levels in adipose tissue of rats fed beef tallow $(0.28$ for PR and 0.32 for SC). The main saturated FA (palmitic and stearic acids) had higher deposition index values $(>2)$ for both adipose tissue sites in rats fed either sunflower oil or olive oil, but not in rats fed palm oil. The deposition index of oleic acid, one of the main dietary FA present in palm oil, was approximately 1 in rats fed palm oil.

The deposition index of TAG molecular species was also calculated and is represented in Fig. 2. Olive oil (Fig. 2(a)) and beef tallow (Fig. 2(b)) caused an accumulation of the most polar TAG (ECN 41.4-45.8) in adipose tissue, in relation to the content in the dietary fats. In contrast, the content of some of the most apolar TAG (high ECN, triolein and stearoyl-dioleoyl-glycerol) was even lower than that of the diet. This fact was reflected in a negative tendency, with a decreased storage of TAG with high ECN (olive oil: $y=-1 \cdot 25 \times+62 \cdot 13, r 0 \cdot 801, P=0.003$ for $\mathrm{PR}$ and $y=-1.92 x+95 \cdot 54, r 0.775, P=0.0051$ for SC; beef

Table 7. Deposition index of fatty acids in perirenal (PR) and subcutaneous (SC) adipose tissues from rats fed the experimental diets*

\begin{tabular}{|c|c|c|c|c|c|c|c|c|}
\hline \multirow[b]{2}{*}{ Fatty acids } & \multicolumn{2}{|c|}{ Olive oil } & \multicolumn{2}{|c|}{ Beef tallow } & \multicolumn{2}{|c|}{ Sunflower oil } & \multicolumn{2}{|c|}{ Palm oil } \\
\hline & PR & SC & PR & SC & PR & $\mathrm{SC}$ & PR & $\mathrm{SC}$ \\
\hline $14: 0$ & $12 \cdot 63$ & $15 \cdot 08$ & 0.58 & 0.72 & $12 \cdot 98$ & 14.39 & 0.97 & 0.93 \\
\hline $14: 1 n-5$ & nd & nd & 0.53 & 0.96 & nd & nd & 3.07 & 3.75 \\
\hline $16: 0$ & 1.40 & 1.41 & 0.86 & 0.99 & 2.59 & 2.54 & 0.67 & 0.60 \\
\hline $16: 1 n-9$ & 2.07 & $2 \cdot 62$ & 0.73 & 0.69 & nd & nd & $6 \cdot 89$ & $7 \cdot 27$ \\
\hline $16: 1 n-7$ & 2.83 & 3.31 & $2 \cdot 24$ & 1.57 & 26.09 & 21.57 & 19.94 & $12 \cdot 84$ \\
\hline $18: 0$ & 0.92 & 0.94 & 0.28 & 0.32 & 1.99 & $2 \cdot 10$ & 0.69 & 0.76 \\
\hline $18: 1 n-9$ trans & 0.05 & 0.24 & 0.40 & 0.41 & nd & nd & 0.97 & 0.70 \\
\hline $18: 1 n-9$ & 0.82 & 0.79 & 1.58 & $1 \cdot 28$ & 1.06 & 1.06 & $1 \cdot 20$ & $1 \cdot 20$ \\
\hline $18: 1 n-7$ & 1.08 & 0.96 & 2.92 & $2 \cdot 44$ & 1.50 & 1.42 & $2 \cdot 00$ & 1.67 \\
\hline $18: 2 n-6$ & 1.89 & $2 \cdot 32$ & $5 \cdot 80$ & $7 \cdot 28$ & 0.70 & 0.69 & 1.30 & 1.63 \\
\hline $18: 3 n-3$ & 0.85 & 0.81 & 3.36 & 3.32 & 0.98 & 0.83 & 0.51 & 0.88 \\
\hline $20: 0$ & 4.78 & 0.77 & 1.58 & $1 \cdot 89$ & nd & nd & 0.25 & 0.27 \\
\hline $20: 1 n-9$ & 0.65 & 1.41 & $1 \cdot 71$ & $2 \cdot 30$ & 0.44 & 0.53 & $2 \cdot 28$ & $2 \cdot 01$ \\
\hline
\end{tabular}

nd, not detected.

* For details of fatty acid and triacylglycerol composition of dietary fat, see Tables 1 and 2, and for details of experimental procedures, see p. 766. 


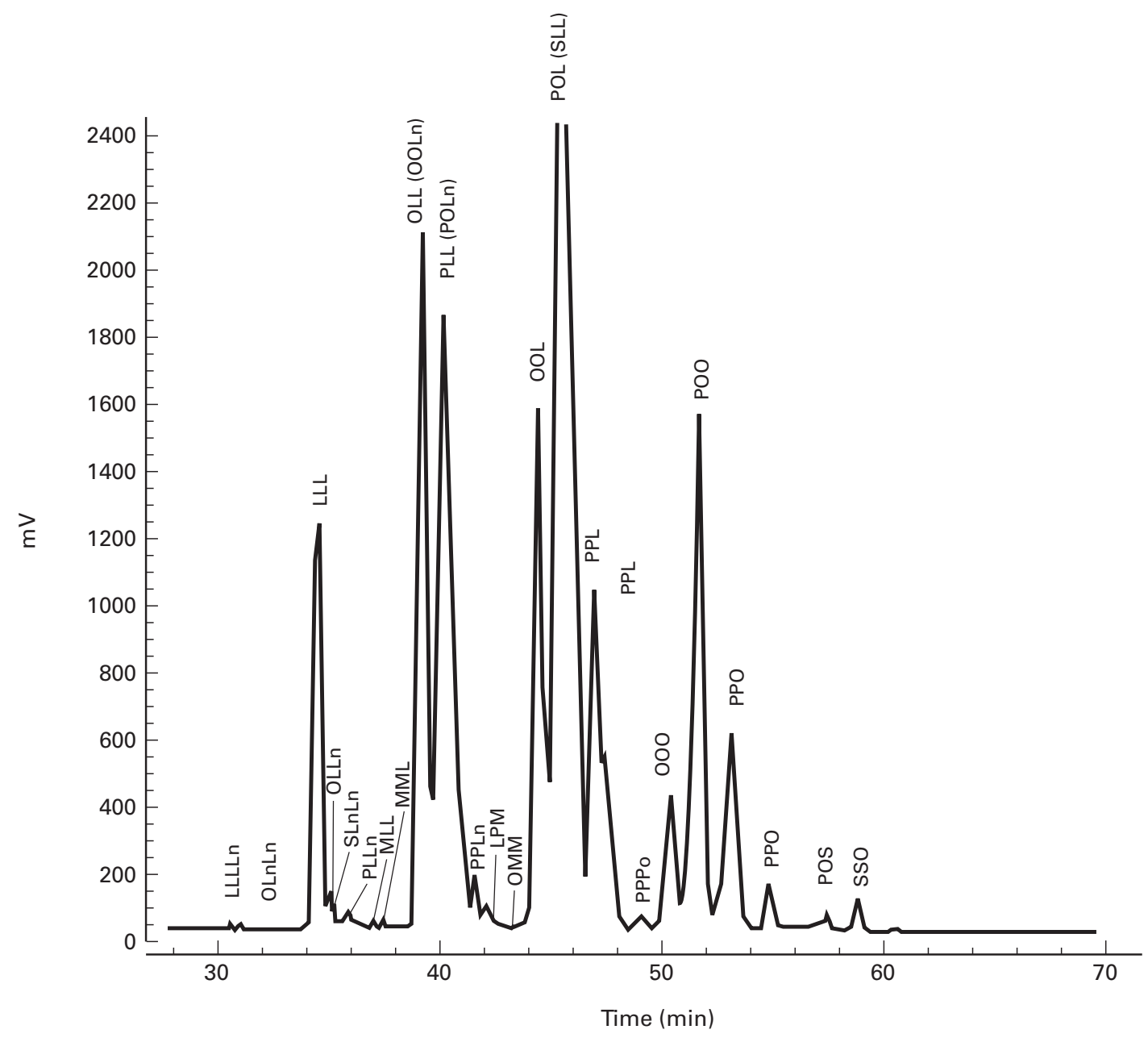

Fig. 1. Triacylglycerol (TAG) molecular species chromatogram of rat adipose tissue by HPLC. For details of elution conditions, see $\mathrm{p}$. 767. M, myristic acid, 14:0; P, palmitic acid, 16:0; S, stearic acid, 18:0; O, oleic acid, 18:1; L, linoleic acid, 18:2; linolenic acid, 18:3; PPP, tripalmitoylglycerol; LPM, linoleoyl-palmitoyl-myristoyl-glycerol; PLL, palmitoyl-dilinoleoyl-glycerol.

tallow: $y=-0 \cdot 54 x+26 \cdot 88, r 0 \cdot 788, P=0 \cdot 004$ for PR and $y=-1 \cdot 95 x+95 \cdot 28, r 0 \cdot 837, P=0 \cdot 0013$ for SC). Such an effect was not observed for sunflower oil (Fig. 2(c)) or palm oil (Fig. 2(d)) (sunflower oil: $y=1.65 x-68.93, r$ $0 \cdot 234, P=0.1198$ for $\mathrm{PR}$ and $y=1.44 x-59 \cdot 58, r 0.210$, $P=0.2658$ for SC; palm oil: $y=0.22 x-7.54, r 0.276$, $P=0.4122$ for PR and $y=0.18 x-5.41, r 0.126, P=$ 0.5269 for SC), although sunflower oil was responsible for the specific deposition of triolein, dipalmitoyl-oleoylglycerol and dipalmitoyl-linoleoyl-glycerol.

\section{Discussion}

The present work was performed in order to study the deposition of dietary TAG from different origins (olive oil, beef tallow, sunflower oil or palm oil) in rat adipose tissues. It is well known that during high-fat feeding the FA composition of TAG in adipose tissue largely reflects that of the diet (Lin \& Connor, 1990). A similar finding was also obtained in the present study. The main FA of the dietary fats were present in the adipose tissue of the animals, in most cases in similar proportions. However, differences were found between the dietary and adipose tissue contents of minor fatty acids, which suggests that dietary FA composition is altered between ingestion and deposition in adipose tissue. It has been suggested that when a diet provides a high amount of a specific FA, a restructuring and synthesis of TAG takes place to protect the tissues from sudden changes (Fielding et al. 1996; Lambert et al. 1996). This process has been observed to start in the intestine. This effect was shown when the values of FA deposition index were calculated for each dietary fat (Table 7). High values for deposition index were obtained for the minor FA. The myristic acid content (14:0) was increased more than 10-fold in the adipose tissue of rats fed olive oil or sunflower oil compared with the dietary fats, suggesting de novo synthesis. Similarly, palmitoleic acid $(16: 1 n-7)$ content was raised in the adipose tissue of rats fed sunflower oil or palm oil, with values for deposition index of about 20, suggesting an increase in the desaturation of palmitic acid. Lin et al. (1993) reported that, in general terms, the FA composition of dietary lipids is conserved in the adipose tissue of rabbits. However, despite using the deposition index, they did not calculate values for minor 
(a) Olive oil

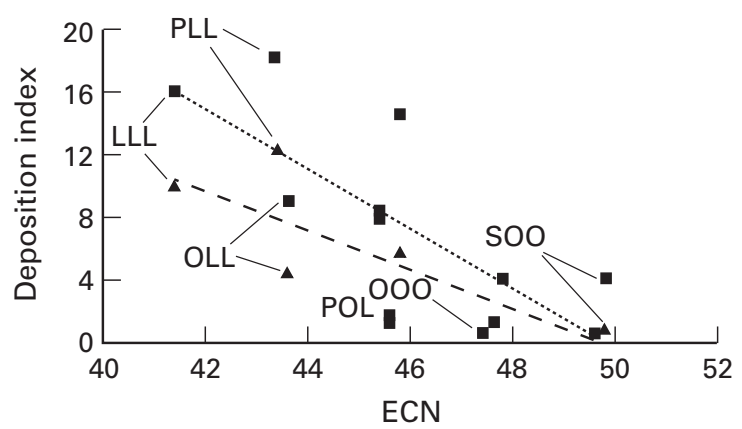

(c) Sunflower oil

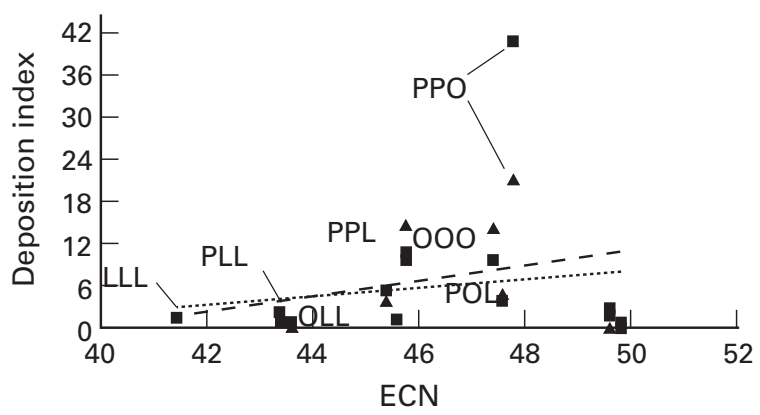

(b) Beef tallow

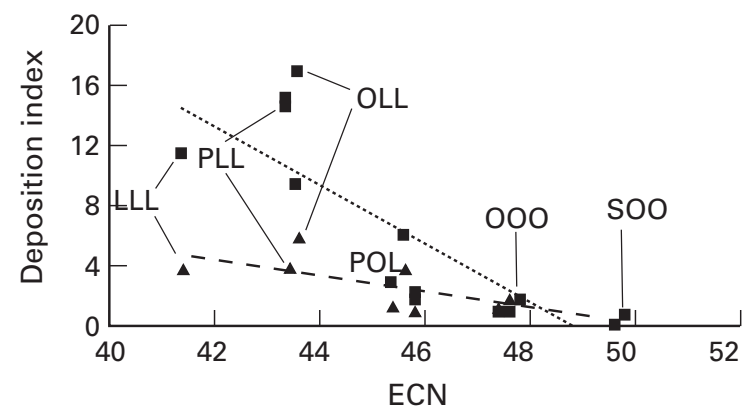

(d) Palm oil

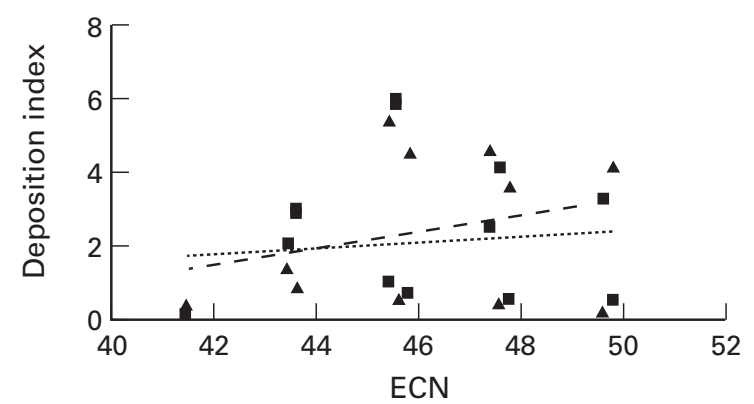

Fig. 2. Deposition index $v$. the equivalent carbon number $(E C N)$ of triacylglycerols in perirenal (PR; $\mathbf{\Delta}---\mathbf{\Lambda})$ and subcutaneous (SC; $\mathbf{\square} \ldots . . \mathbf{\square})$ adipose tissues from rats fed (a) olive oil, (b) beef tallow, (c) sunflower oil and (d) palm oil. The deposition index (the relationship between triacylglycerol composition of adipose tissue and that of dietary fat) and ECN (an index of polarity) were calculated as described on p. 769. LLL, trilinolein; PLL, palmitoyl-dilinoleoyl-glycerol; OLL, oleoyl-dilinoleoyl-glycerol; PPL, dipalmitoyl-linoleoyl-glycerol; OOO, triolein; SOO, stearoyldioleoyl-glycerol; PPO, dipalmitoyl-oleoyl-glycerol; POL, palmitoyl-oleoyl-linoleoyl-glycerol. (A) PR $r$ 0.801, SC $r$ 0.775; (B) PR $r$ 0.788, SC $r$ 0.837; (C) PR r 0.234, SC r 0.210; (D) PR r 0.276, SC r 0.126.

fatty acids, which show the greatest differences in the present study.

The composition of adipose tissue affects the release of FA into the bloodstream. It has been suggested that the release process is selective, based on the polarity of the stored FA rather than on the specificity of hormonesensitive lipase; i.e., the more polar a FA (low number of $\mathrm{C}$ atoms or high extent of unsaturation), the easier the access to hormone-sensitive lipase and thus, its hydrolysation (Gavino \& Gavino, 1992; Connor et al. 1996; Raclot, 1997). This relationship would imply that, depending on their polarity, FA would be more or less rapidly released. However, it is evident that as FA are stored as TAG molecules in adipose tissue, their accessibility will be dependent on the molecular polarity of the TAG.

The TAG molecular species in the rat adipose tissue (Tables 5 and 6) were enriched with the FA characteristic of each dietary fat source. Palm oil and beef tallow were responsible for the accumulation of TAG containing saturated FA. As expected, we found important amounts of stearic acid-containing TAG in the adipose tissue of rats fed beef tallow, but we were surprised by the high content in dioleoyl-linoleoyl-glycerol observed in the adipose depot of rats consuming the palm-oil-enriched diet. This TAG was also found in notable amounts in the adipose tissue of rats fed olive oil or sunflower oil. Actually, the deposition index was about 4.5 in rats fed sunflower oil, about 5.5 in rats fed palm oil and about $8 \cdot 0$ in rats fed olive oil. It seems that there is a need to accumulate dioleoyl-lindeoylglycerol in rat adipose tissue. Sunflower oil was responsible for adipose tissue enrichment with the most polar TAG (trilinolein, dilinoleoyl-oleoyl-glycerol and dilinoleoylpalmitoyl-glycerol). This finding is in good agreement with those of Huang et al. (1992) in rat adipose tissue; they reported that a diet highly enriched with linoleic acid may cause linoleic acid to replace other FA in the TAG molecules, increasing the content of dilinoleoyl-acylglycerol species. In olive oil, the content of dilinoleoyl species was very low, while dioleoyl species accounted for about $70 \mathrm{~g} / 100 \mathrm{~g}$ total TAG. Recently, we have found similar amounts in the liver of rats fed olive oil (Perona $\&$ Ruiz-Gutiérrez, 1998; Perona et al. 1998b). Thus, not only the TAG composition of adipose tissue but also that of other organs might be modified via the diet, with evident physiological implications (Chen \& Cunnane, 1992, 1993; Chen et al. 1992). It is very likely that TAG containing long-chain polyunsaturated FA were present in adipose tissues, but our chromatographic system was not able to detect them. (These TAG only account for $2 \mathrm{~g} / 100 \mathrm{~g}$ total TAG.)

When we plotted the deposition index values for some of the main TAG $v$. their corresponding ECN, we found important differences in the effects of diet. While rats fed diets enriched with olive oil or beef tallow showed a 
tendency to accumulate polar TAG (low ECN), neither this nor the tendency to accumulate apolar TAG (high ECN) was observed in rats fed sunflower oil or palm oil. The accumulation of TAG in response to a diet enriched with palm oil showed comparatively lower deposition index values for the TAG species studied. In contrast, some TAG were specifically accumulated in the adipose tissue of rats fed sunflower oil, in relation to their content in the oil. Despite the fact that linoleic-acid-containing TAG are in the majority in the adipose tissue of these rats, the deposition index values for dipalmitoyl-linoleoyl-glycerol, dipalmitoyl-oleoyl-glycerol and triolein were $>10$. We must emphasize that these TAG are minor TAG in sunflower oil $(<1 \mathrm{~g} / 100 \mathrm{~g}$ total TAG). Thus, it seems that there is a need to accumulate these TAG in rat adipose tissue when a diet containing relatively polar TAG is fed. The increase in saturated FA in the TAG species of rat adipose tissue might be related to a requirement for these FA for metabolic functions leaving linoleic acid for other physiological functions. In addition, linoleic acid-containing TAG (trilinolein, oleoyl-dilioleoyl-glycerol, palmitoyldilinoleoyl-glycerol and palmitoyl-oleoyl-linoleoyl-glycerol) showed low deposition index values in the adipose tissue of rats fed a diet rich in this FA. This factor suggests that an excess of linoleic acid is diverted towards other physiological functions. However, when the diet is low in linoleic acid (olive oil and beef tallow), the animal tends to accumulate TAG containing linoleic acid, which are oxidized more slowly. This finding is in agreement with the work of Chen \& Cunnane (1991), who reported an increase in these TAG in fasting rats.

In general, similar FA profiles and TAG compositions were observed in adipose tissue from both anatomical sites, in all groups. Slight differences between PR and SC depots were observed only in rats fed beef tallow.

In summary, we have found that the process of FA and TAG deposition in rat adipose tissue is selective, and depends on the composition of the diet. This finding has important implications for obesity and its related pathologies, since the depletion of lipids stored in adipose tissue by TAG hydrolysis is related to the composition of the tissue. Mobilization of TAG stored in the adipose tissues from rats fed diets enriched with sunflower oil may be related to the high content of the most-polar TAG species (trilinolein, dilinoleoyl-oleoyl glycerol and dioleoyl-palmitoyl-glycerol). We believe that it is not sufficient to determine the FA composition in the study of TAG hydrolysis from adipose tissue: the composition of the TAG molecular species must also be considered, as the molecular polarity of TAG seems to be a determinant in the process of FA release.

\section{Acknowledgements}

This work was supported by grants (OLI96-2126 and ALI99-0863) from the Comisión Interministerial de Ciencia y Tecnología (CICYT) and the Government of the País Vasco (PI 96/22) and by a fellowship from this Government. We are grateful to Fernanda Leone for performing the analysis and for her excellent technical assistance.

\section{References}

Abia R, Perona JS, Pacheco YM, Montero E, Muriana FJG \& Ruiz-Gutiérrez V (1999) Postprandial triacylglycerols from dietary virgin olive oil are selectively cleared in humans. Journal of Nutrition 129, 2184-2191.

Belzung F, Raclot T \& Groscolas R (1993) Fish oil $n-3$ fatty acids selectively limit the hypertrophy of abdominal fat depots in growing rats fed high-fat diets. American Journal of Physiology 264, R1111-R1118.

Botham KM, Avella M, Cantatora A \& Bravo E (1997) The lipolysis of chylomicrons derived from different dietary fats by lipoprotein lipase in vitro. Biochimica et Biophysica Acta 1349, 257-263.

Calder PC, Harvey DJ, Pond CM \& Newsholme EA (1992) Sitespecific differences in the fatty acid composition of human adipose tissue. Lipids 27, 716-720.

Chen ZY \& Cunnane SC (1991) Short-term energy deficit causes net accumulation of linoleoyl-enriched triacylglycerols in rat liver. FEBS Letters 280, 393-396.

Chen ZY \& Cunnane SC (1992) Early postnatal development in the rats is characterized by accumulation of high unsaturated triacylglycerols. Pediatric Research 31, 47-51.

Chen ZY \& Cunnane SC (1993) Fasting-induced remodelling of hepatic triacylglycerols. Journal of Nutritional Biochemistry $\mathbf{4}$, 421-425.

Chen ZY, Yang J, Menard CR \& Cunnane SC (1992) Linoleoylenriched triacylglycerol species increase in maternal liver during late pregnancy in the rat. Lipids 27, 321-324.

Connor WE, Lin DS \& Colvis C (1996) Differential mobilization of fatty acids from adipose tissue. Journal of Lipid Research 37, 290-298.

Crawford MA (1983) The relationship between fatty acids and their prostanoid derivatives prostaglandins. In Biology and Chemistry of Prostaglandin Related Eicosanoids, pp. 517-531 [Curtis-Prior PB, editor]. Edinburgh: Livingstone.

Fielding BA, Callow J, Owen RM, Samra JS, Matthews D \& Frayn KN (1996) Postprandial lipemia: the origin of an early peak studied by specific dietary fatty acid intake during sequential meals. American Journal of Clinical Nutrition 63, 36-41.

Folch J, Leess M \& Sloan Stanley GH (1957) A simple method for the isolation and purification of total lipids from the animal tissues. Journal of Biological Chemistry 33, 497-509.

Gavino VC \& Gavino GR (1992) Adipose hormone-sensitive lipase preferentially releases polyunsaturated fatty acids from triglycerides. Lipids 27, 950-954.

Huang YS, Lin X, Smith RS, Redden PR, Jenkins DK \& Horrobin DF (1992) Effect of dietary linoleic acid content on the distribution of triacylglycerol molecular species in rat adipose tissue. Lipids 27, 711-715.

Lambert MC, Botham KM \& Mayes P (1996) Modification of the fatty acid composition of dietary oils and fats on incorporation into chylomicrons and chylomicron remnants. British Journal of Nutrition 76, 435-445.

Lin DS \& Connor WE (1990) Are the $n-3$ fatty acids from dietary fish oil deposited in the triglyceride stores of adipose tissue? American Journal of Clinical Nutrition 51, 535-539.

Lin DS, Connor WE \& Spenler CW (1993) Are dietary saturated, monounsaturated and polyunsaturated fatty acids deposited to the same extent in adipose tissue of rabbits? American Journal of Clinical Nutrition 58, 174-179.

Marchington JM \& Pond CM (1990) Site specific properties of pericardial and epicardial adipose tissue: the effects of insulin and high fat feeding on lipogenesis and the incorporation of fatty acids in vitro. International Journal of Obesity 14, 10131022. 
Nájera AI, Barcina Y, Renobales M \& Barrón LJR (1998) Changes in triacylglycerols during ripening of Idiazabal cheese. Journal of Agricultural and Food Chemistry 46, 3252-3256.

Perona JS, Barrón LJR \& Ruiz-Gutiérrez V (1998a) Molecular prediction of rat liver triglycerides by high performance liquid chromatography. Journal of Liquid Chromatography 21, 11851197.

Perona JS, Barrón LJR \& Ruiz-Gutiérrez V (1998b) Determination of rat liver triglycerides by gas-liquid chromatography and reversed-phase high-performance liquid chromatography. Journal of Chromatography 706B, 176-179.

Perona JS \& Ruiz-Gutiérrez V (1998) Two highly monounsaturated oils, olive oil and high-oleic sunflower oil, induce different triacylglycerol molecular species distribution in rat liver. Nutrition Research 18, 1723-1732.

Perona JS \& Ruiz-Gutiérrez V (1999) Characterization of the triacylglycerol molecular species of fish oil by high-performance liquid chromatography. Journal of Liquid Chromatography and Related Technologies 22, 1699-1714.

Portillo MP, Tueros AI, Perona JS, Ruiz-Gutiérrez V \& Macarulla MT (1999) Modifications induced by dietary lipid source in adipose tissue phospholipid fatty acids and their consequences in lipid mobilization. British Journal of Nutrition 82, 319-327.

Portillo MP, Villaro JM \& Macarulla MT (2000) In vivo lipolysis in adipose tissue from two anatomical locations measured by microdialysis. Life Sciences 67, 437-445.

Raclot T (1997) Selective mobilization of fatty acids from white fat cell: evidence for a relationship to the polarity of triacylglycerols. Biochemical Journal 322, 483-489.

Raclot T \& Groscolas R (1995) Selective mobilization of adipose tissue fatty acids during energy depletion in the rat. Journal of Lipid Research 36, 2164-2173.

Raclot T, Leray C, Bach AC \& Groscolas R (1995) Selective mobilization of fatty acids is not based on their positional distribution in white-fat-cell triacylglycerols. Biochemical Journal 311, 911-916.

Richelsen B, Pedersen SB, Moller-Pedersen T \& Back JF (1991) Regional differences in triglyceride breakdown in human adipose tissue: effects of catecholamines, insulin and prostaglandin $\mathrm{E}_{2}$. Metabolism 40, 990-996.

Ruiz-Gutiérrez V, Montero E \& Villar J (1992) Determination of fatty acid and triacylglycerol composition of human adipose tissue. Journal of Chromatography 581, 171-178.

Thomas LH, Jones PR, Winter JA \& Smith H (1981) Hydrogenated oil and fats: the presence of chemically-modified fatty acid in human adipose tissue. American Journal of Clinical Nutrition 34, 877-886.

Wang CS, Hartsuck J \& McConathy WJ (1992) Structure and functional properties of lipoprotein lipase. Biochimica et Biophysica Acta 1123, 1-17. 